Психология. Журнал Высшей школы экономики.

2017. T. 14. № 4. C. 626-643. DOI: 10.17323/1813-8918-2017-4-626-643

\title{
В.П. ЗИНЧЕНКО И СТАНОВЛЕНИЕ ИНЖЕНЕРНОЙ ПСИХОЛОГИИ В СССР
}

\author{
Г.Л. СМОЛЯН
}

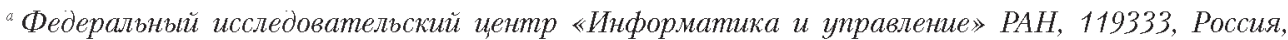
Москва, ул. Вавилова, д. 44, корп. 2

\begin{abstract}
Резюме
В статье дан обзор трудов В.П. Зинченко в области инженерной психологии в период от начала 1960-х до середины 1970-х гг. Они сформировали концептуалыный каркас, определили содержание и границы предметной области инженерной психологии (ИП) как самостоятельной ветви прикладной психологии и сыграли кардинальную роль в создании и развитии в 1960 г. лаборатории инженерной психологии в НИИ автоматической аппаратуры, головной лаборатории по учету человеческого фактора при проектировании и эксплуатации человеко-машинных систем обработки информации и управления, а в 1969 г. отдела эргономики ВНИИТЭ - центра методологических разработок в области создания технических средств, управляемых или используемых человеком. Работы В.П. Зинченко и его сотрудников заложили методологическую основу многочисленных стандартов и руководств, содержацих практические рекомендации по оптимизации деятельности операторов автоматизированных систем, в частности комплекса ГОСТов на системы «человекмашина». Все работы В.П. Зинченко тематически подразделены на пять блоков.
\end{abstract}

Ключевые слова: инженерная психология, система «человек-машина», АСУ, человек-оператор, анализ операторской деятельности, информационная модель.

\section{Первые шаги}

Начиналась служба инженерной психологии в НИИ автоматической аппаратуры так.

В 1960 г. заведующий теоретическим отделом НИИ Д.Ю. Панов пригласил на работу небольшой коллектив психологов, работавших в МГУ и в Психологическом институте во главе с молодым талантливым ученым, кандидатом психологических наук В.П. Зинченко.

Д.Ю. Панов был проницательным и мудрым человеком и хорошо понимал, что создание систем управле- ния, особенно высших звеньев, невозможно без тщательного учета психологии человека. В последующем при непосредственной поддержке генерального конструктора института В.С. Семенихина сотрудники В.П. Зинченко стали коллективом лаборатории инженерной психологии, головной в оборонных отраслях промышленности. Сотрудники лаборатории принимали участие в проектировании и экспертизе рабочих мест и средств отображения информации.

Институт поддерживал интересные экспериментальные работы по 
изучению процессов зрительного восприятия и кратковременной памяти, проводимые сотрудниками лаборатории на базе институтских ЭВМ. В.П. Зинченко был контактным, неизменно доброжелательным и остроумным человеком. Ему симпатизировали главные конструкторы проектируемых АСУ, поэтому недостатка в испытуемых у экспериментаторов не было. Фактически в этом НИИ в 1960-е гг. был осуществлен первый в СССР реальный опыт поддержки научных исследований академического или университетского профиля со стороны «богатых» оборонных отраслей.

Нужно признать, что Владимир Петрович существенно обогатил инженерный менталитет опытом гуманитарного образа мышления и психологической культуры. Влияние психологов было значительным, способные люди тянулись к ним.

Важно подчеркнуть, что с создания этой лаборатории началось становление инженерной психологии (ИП) в СССР. Авторами первых основополагающих работ по инженерной психологии являлись В.П. Зинченко, А.Н. Леонтьев (в те годы декан факультета психологии МГУ) и Д.Ю. Панов (Зинченко, Панов, 1962; Зинченко и др., 1964; Зинченко, Леонтьев, Панов, 1964). В.П. Зинченко, ставший в 1967 г. доктором наук, определил главную особенность деятельности человека-оператора как деятельность с информационными моделями. Это открыло новый путь совершенствования средств отображения информации (СОИ), так как позволило решать на прочной научной основе задачи кодирования информации, выбора форм и способов ее представления на экранах, мнемосхемах и табло. Важное место в деятельности лаборатории занимали разработка инженерно-психологических требований к средствам отображения информации и контроль нал заданием этих требований в проектно-конструкторской документации.

Научно-практические разработки лаборатории получили высокую оценку создателей автоматизированных систем, а инженерная психология - признание как важнейшая область психологической науки. Это нашло отражение в создании кафедры психологии труда и инженерной психологии на факультете психологии МГУ (1970) и отдела эргономики и инженерной психологии во ВНИИ технической эстетики (1969), которые возглавил В.П. Зинченко.

Яркий талант В.П. Зинченко как организатора науки основывался на выраженной широте научных интересов, глубоком понимании традиций, открытости новым идеям, чутье экспериментатора, способности не только легко и ярко излагать идеи и результаты исследований, но и демонстрировать перспективы их концептуального развития и практического использования.

\section{Краткий обзор работ В.П. Зинченко ${ }^{1}$}

Инженерно-психологические работы В.П. Зинченко тематически

Все тексты трудов В.П. Зинченко любезно представлены мне супругой Владимира Петровича Натальей Дмитриевной Гордеевой. Приношу ей искреннюю благодарность. 
подразделяются на 5 блоков (их список приведен в конце статьи).

Первый блок составляют работы фундаментального характера (теоретические и методологические основания ИП, цели, задачи и содержание деятельности человека-оператора, распределение функций между человеком и машиной, инженернопсихологическое обеспечение разработки и эксплуатации автоматизированных систем) - это работы № 1-4 и более поздняя методологическая работа № 5.

Второй блок - работы, содержащие результаты экспериментальных исследований закономерностей и характеристик отдельных процессов в операторской деятельности, в том числе с использованием ЭВМ (№ 6-9).

третийблок - работы, касающиеся связи ИП и других областей знания, смежных и более отдаленных (информатика, дизайн, рефлексивное управление), их № 10-12.

Четвертый блок представляют работы просветительского характера, популяризация ИП, гуманитаризация инженерного образования и критика технократического образа мышления, это работы № 13-16.

Наконец, пятый блок представлен работами № 17, 18, суммирующими в известном смысле вклад инженерной психологии в создание автоматизированных систем.

Рассмотрим основные концептуальные положения в работах каждого блока.

\section{Первый блок}

Уже в самой ранней работе (Зинченко, Панов, 1962) были сформулированы базовые направления иссле- дований, получившие развитие в последующих работах в течение целого десятилетия:

- предмет и задачи ИП;

- особенности исследуемой проблематики;

- определение места и статуса ИП в системе наук;

- выявление методологического ядра ИП.

В.П. Зинченко как профессиональный психолог справедливо подчеркивал, что прогнозы о вытеснении в ближайшем будущем человека из системы «человек-машина» преждевременны, что задача ИП заключается, прежде всего, в обеспечении надежной и эффективной работы оператора в автоматизированной системе управления, в согласовании рабочих характеристик оператора с характеристиками автоматических устройств, а для этого необходимо понимание того, что деятельность оператора в автоматизированной системе управления представляет собой новый вид трудовой деятельности.

Поскольку первой сушественной особенностью деятельности человека в автоматизированной системе является новая опосредствованная форма получения информации об управляющих и управляемых объектах, в качестве предмета инженерной психологи выделяется деятельность оператора с информационними моделями, заместителями реальных управляемых объектов.

При анализе систем «человекмашина» возникает задача распределения функций между человеком и машиной с целью обеспечения максимальной надежности, помехоустойчивости и требуемого временно́го режима работы. 
В процессе решения этой задачи обнаруживаются «узкие места» как машины, так и человека и возникают конкретные задачи автоматизации тех операций, которые ненадежно выполняются человеком, или передачи человеку тех операций, с выполнением которых плохо справляется машина. Возможны, конечно, и другие решения: специальный подбор и обучение оператора, внесение конструктивных изменений в машину и т.д. Проектировщику $\mathrm{AC}$ У необходимо как можно полнее использовать то, что известно о функциональных возможностях человека. Систематизация этих сведений поможет, во-первых, лучше использовать приспособительные и творческие возможности человека и, вовторых, избавиться от просчетов в проектировании, следствием которых часто является неэффективная и ненадежная работа оператора. В этой статье выделены специфические проблемы инженерной психологии, в значительной степени отличающие eе от традиционной психологии труда.

В работе 1964 г. (Зинченко, Леонтьев, Панов, 1964) проведено уточнение представления о деятельности c информационными моделями. Авторы четко формулируют: осмысливание информации, предьявляемой оператору с помощью информационной модели, требует, чтобы при создании такой модели учитывались психофизиологические возможности человека-оператора. Объем информации того или иного рода, который может быть хорошо усвоен оператором, не может быть задан ему произвольно. Он должен быть определен для данных условий работы или на основе уже имеющихся инженерно-психологических исследований, или при помощи специального эксперимента, так как во многих случаях таких данных, к сожалению, не имеется.

Центральной задачей инженерной психологии является выработка требований к информационным моделям и способов построения моделей, в максимальной степени учитывающих фунциональные характеристики и возможности опеpatopa.

В другой работе (Панов, Зинченко, 1964) возникновение инженерной психологии и определение ее статуса в системе знания непосредственно связывалось с техническим прогрессом. Решаюшую роль в формировании этой отрасли науки, писали авторы, сыграло развитие сложного технического оснащения промышленности, авиации и других видов транспорта и средств связи, а также быстрое развитие кибернетики, теории информации и радиоэлектроники. Технический прогресс внес в проблему «человек и машина» существенно новое содержание. Именно поэтому инженерная психология должна рассматриваться не как вспомогательная для техники дисциплина, целиком подчиненная ее задачам, а как ведущий раздел психологи трудовой деятельности человека.

Возникновение, развитие и совершенствование автоматизированных устройств меняют содержание процессов, которые являются характерными для трудовой деятельности; оно намного усложняет, обогащает и «интеллектуализирует» их и таким образом является важным фактором дальнейшего психического развития. 
Традиционная проблематика психологии, физиологии и гигиены труда, подчеркивают авторы, отнюдь не выпадает из поля зрения инженерной психологии. Напротив, значительное число проблем, выдвинутых психологией труда, а также выработанные в ней приемы исследования должны быть иснользованы и при проектировании автоматизированных устройств. К специальным вопросам, которые непосредственно относятся к области инженерной психологии, следует отнести выработку критериев надежности, точности, помехоустойчивости, степени психической напряженности, утомления в работе операторов.

Фундаментальной следует считать работу группы авторов (Зинченко и др., 1964), посвященную анализу деятельности человека-операmopa

Разработка принципов анализа деятельности операторов автоматизированных систем, исследование ее специфических черт, особенностей ее структуры и психологического содержания необходимы для решения целого ряда практических вопросов, возникающих при проектировании систем управления. К таким вопросам относятся следующие.

1. Оптимальная организация деятельности оператора. Это основная проблема, разработка которой включает решение следующих частных вопросов:

а) распределение функций между человеком и маииной. Современные системы управления предполагают совместную работу человека и машины и требуют чрезвычайно четкого согласования их функций; реализация этого требования возможна только при правильном распределении функций между ними;

б) взаимодействие людей в системе управления. Правильное распределение функций между отдельными операторами не менее важно, чем распределение функций между человеком и машиной;

в) пропускная способность человека. Имеется в виду, во-первых, объем и скорость приема информации пропускная способность сенсорных «входов» оператора. Во-вторых, изучению подлежат скорость переработки информации и принятия решения и, наконец, пропускная способность «выхода» - скорость речевых и двигательных ответных реакций;

г) установление критериев и условий точности и надежности работы оператора, что, в свою очередь, предполагает необходимость исследования таких вопросов, как утомление, стресс и др. (условия их возникновения, динамика, методы регистрации, влияние на выполняемую деятельность).

2. Второй крупной задачей является выработка адекватных и эффективных методов обучения. Анализ деятельности оператора является необходимой предпосылкой для правильной организации процесса обучения, от результатов которого во многом зависит качество будущей работы оператора.

3. Без достаточно полного и конкретного анализа деятельности оператора немыслимо разрешение проблемы отбора. Решение практических проблем инженерной психологии и разработка соответствующих рекомендаций производятся обычно в расчете на «среднего» человека; 
при этом исходят из общих закономерностей его психической деятельности, в то время как осуществление отбора производится на основании индивидуальных особенностей человека. Проблема отбора оказывается одной из насущных, особенно в тех видах деятельности, в которых даже небольшая ошибка оператора может привести к тяжелым последствиям (например, в системах специального назначения).

Авторы представили классификацию операторских функций, которая стала фактически общепринятой и в дальнейшем широко использовалась. Она существенно облегчает систематизацию данных, необходимых для учета человеческого фактора при создании новой техники.

В.П. Зинченко специально подчеркивал, что психологическая теория деятельности теснейшим образом связана с прикладными областями психологии. Между этой теорией и ее практическими приложениями непрестанно происходят обмен и взаимообогащение идеями, концептуальными схемами, методами и результатами. В ряде отраслей психологии эта теория достигла высоких уровней операционализации. Не составляет исключения и инженерная психология.

\section{Второй блок}

Исследования отдельных психологических и инженерно-психологических проблем, в том числе экспериментальные исследования с использованием ЭВМ, имеющие непосредственное отноптение к оптимизации деятельности операторов ACY.
В этом блоке представлены работы: Зинченко, Гордон, 1971; Зинченко, 1972; Зинченко, Труш, 1978; Панин, Зинченко, 1970. В этих работах В.П. Зинченко проявил себя, вопервых, как специалист по восприятию высшей квалификации и, вовторых, как ученик А.Н. Леонтьева, творчески развивающий психологическую теорию деятельности.

Начнем с исследований информационных моделей и информационного поиска (Панин, Зинченко, 1970). В.П. Зинченко связал задачу построения информационных моделей с закономерностями психологии восприятия. Он установил четкую типологию операций информационного поиска, а также разработал методику количественной оценки его характеристик. В статье содержатся прямые рекомендации, которые в дальнейшем легли в основу разработки многих государственных и отраслевых стандартов на средства отображения в АСУ. Заключение этой сугубо прикладной работы имеет важное теоретическое значение. В частности, авторы отмечали, что традиционный теоретико-информационный подход к анализу процессов взаимодействия оператора со средствами представления информации недостаточен. Основанная на использовании понятия энтропии оценка количества информации, содержащейся в информационной модели и воспринимаемой оператором, игнорирует, по существу, содержательную и наиболее драматическую сторону работы оператора с моделью.

В статье, посвященной микроструктурному анализу познавательной деятельности (Зинченко, 1972), 
вводятся различные категории и концептуальные схемы, в рамках которых описывается познавательная деятельность. К ним относятся категории традиционной функциональной психологии (ощущение, внимание, память и другие психические функции), генетической психологии, нейропсихологии, а также категории относительно недавно сложившегося информационного подхода и др. Различные единицы анализа и недостаточно дифференцированное употребление их в научной психологической литературе неминуемо создают определенные препятствия и трудности понятийного, методологического и методического характера. Эти трудности имеются как в общей и экспериментальной психологии, так и в прикладных областях. Для преодоления указанных трудностей необходима разработка новой концептуальной схемы и, соответственно, новой методологии исследования познавательной деятельности.

В этой схеме речь должна идти о выработке некоторой новой шкалы элементов анализа познавательной деятельности, с помощью которой оказалось бы возможным, во-первых, охватить весь процесс в целом и, вовторых, составить максимально информативный перечень, или алфавит, преобразований входной информации. Несмотря на крайнюю заманчивость использования в качестве такой шкалы категорий генетической концептуальной схемы (деятельность, действие, операция) или категорий информационного подхода, это не представляется возможным. Более целесообразно использование понятия «функциональный блок» как некоторой структурной единицы алфавита преобразований входной информации с тем, чтобы с помощью этого алфавита могла быть описана та или иная сложная функциональная система.

Понятие блока следует использовать в строго функциональном смысле. При этом должен быть использован весь арсенал новых средств экспериментального исследования (включая методы моделирования и проведения экспериментов с помощью ЭВМ).

В качестве примера В.П. Зинченко приводит перечень потенциально возможных функциональных блоков, участвующих в преобразовании информации на участке от входа зрительной системы до речевого воспроизведения. Эти функциональные блоки были обнаружены в ряде экспериментальных исследований. К числу таких блоков относятся: 1) сенсорная память; 2) иконическая память; 3) сканирование; 4) буферная память узнавания; 5) формирователь программ моторных инструкций или программ экстериоризации; 6) манипулятор невербализованными программами моторных инструкций или программ экстериоризации; 7) блок семантической переработки невербализованной информации; 8) контроль и сличение преобразований, осуществленных в блоках (6) и (7) с иконической памятью; 9) повторение; 10) слуховая вербальная память; 11) воспроизведение.

Некоторые из перечисленных блоков выполняют репродуктивные функции, другие осуществляют продуктивные преобразования входной информации, направленные на приведение ее к виду, пригодному для 
принятия решения или для построения оперативной образно-концептуальной модели проблемной ситуации.

Применение ЭВМ для исследований познавательной и исполнительной деятельности оператора (Зинченко, Труш, 1978). Стремление к построению адекватных моделей человеческой деятельности, считал В.П. Зинченко, требует учета все большего числа факторов и взаимосвязей между ними, что ведет к постоянному усложнению моделей и способов их анализа.

Оказывается, что в большинстве случаев сушествующие модели принципиально невозможно анализировать без вычислительной техники.

Опираясь на опыт работы лаборатории инженерной психологии в НИИ автоматической аппаратуры в середине 1960-х гг., В.П. Зинченко справедливо утверждал, что наиболее эффективный способ применения ЭВМ - постановка управляемых экспериментов, при которых вид информации и время ее предъявления могут изменяться в зависимости от результатов обработки показателей испытуемого. Он подчеркивал, что экспериментальные исследования, основанные на микроструктурной модели и направленные на изучение работы отдельных функциональных блоков и их систем, могут производиться только с помощью современных технических средств (многоканальные тахистоскопы, ЭВМ). Именно в таких исследованиях исключительно ценен режим управляемого эксперимента, позволяющий тестировать выполнение различных операций не по жесткой программе, а с учетом инди- видуальных особенностей испытуемого и изменений его функционального состояния. Более того, применение управляющей ЭВМ с соответствующим набором входных и выходных устройств дает возможность регистрировать, обрабатывать и использовать для управления ходом эксперимента не только поведенческие, но и электрофизиологические характеристики.

Анализ роли зрительной системь в прочессах решения (Зинченко, Гордон, 1971). Развиваемая в этой работе гипотеза заключается в том, что в ходе развития, совершенствования и усложнения функций зрительной системы неоднократно сменяется не только алфавит образов, но и моторный алфавит. Определенная система действий, имеющих собственные физические характеристики, в равной степени необходима на стадиях симультанного опознавания, воспоминания, воспроизведения и решения задач. Задача состояла в том, чтобы обнаружить эффекторные звенья, или моторный алфавит, различные по сложности функциональных органов. Специальный анализ показал, что восприятие стабилизированного изображения идентично восприятию послеобраза.

Результаты экспериментального исследования показывают, что викарные перцептивные действия участвуют в реализации более сложных функций, таких как воспоминание, визуализация и решение задач, и что перцептивные процессы действительно вносят существенный вклад в процесс решения задачи.

По мнению В.П. Зинченко, исследование процесса принятия решения едва ли целесообразно ограничивать 
лишь сферой мышления. Более продуктивным является включение в контекст принятия решения проблематики, получившей название «информационная подготовка решения». К ней относится выявление закономерностей формирования образа, опознания, информационного поиска, иерархической системы преобразований (репродуктивных и продуктивных), осуществляющихся в кратковременной зрительной и слуховой памяти и т.д.

\section{Третий блок}

Здесь представлены работы по смежным областям знания.

Эргономика и информатика (Зинченко, 1986а). В связи с исследованием человеческого фактора особый интерес представляет область, в которой перекрещиваются интересы, задачи и проблемы информатики и эргономики. В этой работе эргономика рассматривается в новом ракурсе.

Есть основания полагать, писал В.П. Зинченко, что опыт выделения, анализа и учета человеческих факторов, накопленный при решении задач эргономического обеспечения СЧМ, может быть использован и развит при решении задач информатики.

Далее следует важное методологическое соображение: информатика и эргономика - каждая из них представляет собой область междисциплинарного исследования. Это положение справедливо теоретически. Практически же междисциплинарность не дана изначально, что означает необходимость поиска стыков между составляющими их дисциплинами.
B информатике, подчеркивает В.П. Зинченко, акцент делается на разработке и создании новых внешних средств деятельности, а в эргономике - на выявлении ранее неизвестных, а также на новых способах формирования известных внутренних средств деятельности, на выявлении резервов человеческого фактора. Таким образом, по отношению к проектированию и оптимизации человеческой деятельности задачи информатики и эргономики являются взаимодополняющими. Каждая из них вовлекает в круг своих интересов результаты и методы психологии, лингвистики, нейропсихологии, социальной и инженерной психологии и других наук. Сотрудничество между ними позволит расширить и углубить междисциплинарный комплекс как информатики, так и эргономики. Далее автор обосновывает актуальность проблематики эргономического обеспечения программных и технических средств вычислительной техники и АСУ, анализирует состояние работ в области искусственного интеллекта и подчеркивает, что и информатика и эргономика остро нуждаются в синтезе психологических знаний.

Важное место в статье занимает проблема понимания в человекомашинных системах, особенно в системах принятия решения, это вызов, пишет В.П. Зинченко, целому семейству гуманитарных наук: психологии, лингвистике, семиотике.

Автор задает ключевой вопрос: как сделать так, чтобы принятие решений было свойством всей человеко-машинной системы и ее главной целевой функцией, но одновременно оставалось прерогативой 
человека? И отвечает: один из продуктивных путей состоит в анализе функциональной структуры предметного человеческого действия, обладающего порождающими свойствами и являющегося источником других форм действия: перцептивных, мнемических, умственных или интеллектуальных.

В заключение автор возвращается к проблематике человеческого сознания. Формирование сознания начинает приобретать вполне практический - социально-экономический и технический смысл. Такой же смысл, какой имеют мастерство, умение, знание. Если к этому не подготовиться, то сознание, как это ни парадоксально, может выступить тормозом научно-технического развития.

Формообразование в дизайне $и$ вопросы визуальной культуры (Зинченко, Устинов, 1975). В этой статье авторы анализируют взаимосвязь зрительного восприятия с творчеством художника-конструктора. Они отмечают сложность профессиональной деятельности художника-конструктора, ее локализацию одновременно в сферах материальной и духовной культуры, трудность ее осмысления в предметах эстетики, социологии, социальной и общей психологии и т.Д.

Важнейшей является категория перцептивного действия, связанная с принципиальной активностью творческих процессов формообразования в художественном конструировании. Однако понимание визуального восприятия как системы перцептивных действий, а самих этих действий как морфологических объектов делает более конкретными, осязаемыми и решаемыми задачи сознательного формирования вещей в творчестве художника-конструктора

По существу, функция перцептивных действий состоит в перцептивной категоризации. Две категории пространства и формь - оказываются важными для работы дизайнера. Вербализуемые преставления о пространстве крайне бедны, как и средства его описания. Перцептивные же представления и средства ориентации в пространстве, напротив, чрезвычайно богаты. Действительно, в ходе сенсорного развития и профессионального обучения человек усваивает различные виды пространства: пространство города, воздушное, подводное, космическое микроскопическое и т.п. В практической жизни в восприятии и осознании пространства человек достаточно легко переходит от одного его вида к другому, хотя они различаются по масштабам и количеству заполняющих объектов, размерам, направлению, положению и скорости перемещения. Естественно, для этого перцептивные категории пространства должны обладать известной мерой абстрактности, обобщенности и инвариантности к конкретному разнообразию и законам движения заполняющих его реальных (или отображенных) объектов, что и позволяет образу пространства эффективно выполнять роль регулятора по отношению к обширным классам исполнительных действий человека. Здесь исключительно важно подчеркнуть, что все эти действия осуществляются на интуитивном, чаще всего невербализуемом уровне.

В соответствии с имеющимися экспериментальными данными переработку зрительной информации 
можно представить как последовательное вовлечение в работу все более высоких уровней описания характеристик объектов, т.е. все новых и новых, все более усложняющихся систем перцептивных действий.

Умение выбирать и фиксировать различные позиции и способы перцепции является, по-видимому, важной составляющей способности к творчеству в области изобразительного искусства. То же имеет место и в области дизайнерского формообразуюшего творчества.

Зрительный образ - это не только и не столько созерцание, сколько воссоздание действительности. Эта конструктивная способность восприятия ведет к пониманию механизма творчества в самом широком смысле. На основе созданных сознанием образов художник-конструктор вновь и вновь обращается к предметной действительности и перестраивает ее в своей практической проектной деятельности. Образы формы, хранящиеся в его памяти, включаясь в манипулятивную систему зрения, составляют основу активного формообразовательного процесса.

В этом смысле искусство, архитектуру, дизайн можно назвать учителями человечества, и главный их урок - продуктивность деятельности, ее творческий характер. Человеческую деятельность, продуктом которой являются новые образы, новые визуальные формы, несущие определенную смысловую нагрузку и создающие значение вещи (явления, проблемы), авторы называют визуальным мыиилением. Что касается искусства, архитектуры и дизайна, то для них визуализация смыслов, визуализация образов - изначальная, органическая прерогатива. Для проблемы формообразования в дизайне этот факт особенно важен.

Таким образом, с точки зрения психологии зрительное восприятие и есть уже творчество, формообразование, по крайней мере, в продуктивных деятельностях - искусстве, архитектуре, дизайне. Овладение закономерностями психологии восприятия, навыками визуального мышления, воспитание формообразуюшего глаза - важнейшее условие, обеспечиваюшее достижение целей дизайна.

Рефлексивные процессы в интернет-взаимодействиях (Зинченко, 2002). В этом несколько неожиданном, богатом ассоциациями и метафорами эссе В.П. Зинченко живо откликнулся на матч Г. Каспарова с шахматной программой, объяснил его проигрыш психологическими причинами, дал оригинальную интерпретацию рефлексивных процессов, затронул некоторые глубинные психологические особенности интернет-взаимодействий, а также во многом предвосхитил современную интернет-игроманию. Он писал:

Непременным условием любого состязания является построение играюиим образа противника. В иахматах в образ противника играюоий встраивает и образ себя самого, но такой образ, каким он видится противнику. Образ построен достаточно детально еще до состязания. При этом функииональныи, стратегиче ский или оперативно-технический nортрет противника всегда дополняется психологическим портретом, реальнымм или мнимым - это безразлиино, но с точки зрения игратощего 
вполне достоверньм. Г. Каспаров не сумел построить нужници образ.

В этом же эссе есть замечательные поэтические строки о шахматах:

они: не только игра (работа, труд, усилие ума), но и кипение страсти. ПІахмать - это, конечно, логика, но и интуиция, разумеется, не беспочвенная, а основанная на опьтие, знании, таланте, гении. Иначе говоря, иахмать - это чудо, тайна, подобная музыке, балету, поэзии.. И будет очень жаль, если эта тайна yйдеm к компьютеру, который не полуиит от владения ею никакого удовольствия...

\section{Четвертый блок}

Разрабатывая базовые принципы инженерной психологии, фактически формируя ее предметную область в начале 1960-х гг. (см. работы первого блока), В.П. Зинченко посвящал немало времени и сил написанию популярных текстов, доступных массовому читателю и способных увлечь перспективой развития новых областей науки и техники. Основную роль здесь сыграло издательство «Знание», выпустив в 1965 г. большим тиражом брошюру «Человек и теника (Системы управления и инженерная психология)» (Зинченко, Смолян, 1965)ㄹ․ О характере изложения можно судить по небольшому отрывку из введения к этой брошюре:
Современная техника создает человеку новые условия труда; можно сказать сильнее: техника создает новый мир, Н роль человека в этом мире отличается от роли Алисы в стране чудес. Человек долюен научиться жить и работать в нем, как он уиился этому в другие эпохи. Поэтому проблематика инженерной психологи довольно тесно переплетается с проблематикой детской психологии. В последней ми, словно при замедленной съемке, можем наблюдать и исследовать формирование поведения в новом для ребенка мире. $И$, несмотря на то, ито в мире ребенка не все устроено так, как ему хотелось бы, привыкнуть к нему все же можн. Во всяком слуиае мир, который создают оператору инженеры, намного хуже, привыкнуть к нему значительно труднее, а порой и невозможно. $K$ тому же оператор, как правило, лииен возможности изменять мир, созданный для него инженерами. Максимум, ито он может сделать, это не нажимать 9 кнопок из 10, предоставленных ему заботливым конструктором...

Еце одно популарное разьяснение сути процессов оперативной переработки информации человеком (Зинченко, 1967). Речь идет о требовании адекватности информационной модели действительной обстановке и задачам оператора.

Спустя два десятилетия уже на другой основе (появились проекты

${ }^{2}$ Справедливости ради заметим, что вышедшая чуть раньше в 1966 г. в издательстве Ленинградского университета книга Б.Ф. Ломова с подобным названием («Человек и техника. Очерки инженерной психологии») была скорее рассчитана на студентов, опиралась во многом на переводные работы и не отличалась легкостью изложения. 
создания Института человека, программы «Экологии культуры», «Гуманизации труда», «Гуманитаризации высшего технического образования») В.П. Зинченко вновь обращается к проблеме перспектив человека в эпоху научно-технической революции, он считает весьма опасными симптомами возникновение и распространение технократических подходов к развитию производства, далеко не всегда обоснованное стремление к «безлюдной технологии», забвение того, что забота о человеке должна быть приоритетной целью социально-экономического развития. Так появилась книга (Зинченко, 1989), центральная идея которой формулировалась так:

Культура должна рассматриваться не только как среда, внешнее условие или обстановка развития, не как один из серии рядопоположных факторов становления сочиотехнииеского мира, а как важнейиий источник, составная часть и движущал сила, определятощие направление и формь его развития. Не среда, а средство, а возможно, и цель развития. Для подобной оценки роли культурь имеются объективные основания, заключенные в самом существе социотехнического мира.

Реальность такова, что научно-технический прогресс, развитие техники оказывает на культуру двоякое влияние - формирующее и деформирующее. За технический прогресс обществу приходится расплачиваться, нередко дорогой ценой. Видимо, эта цена может быть уменьшена при гармонизации отношений между культурой и техникой. Этот процесс шел всегда. Идет он и сейчас, но сейчас он протекает весьма болезненно. Каковы же перспективы культуры? Неужели вновь (в который раз!) возникнет вопрос о ее судьбах? Задавая этот вопрос, В.П. Зинченко щедро цитирует О.Э. Мандельштама, Б.Л. Пастернака, А.А. Блока. В конце заключает:

Источник оптимизма состоит в том, что люди если и не твердо знают, то, во всяком случае, чувствуют, ито самая верная их защитница - это культура, а самьй опасньии враг - это бескультурье. К сожалению, это известно и людям крайне далеким от культуры, котоpые умент все обращать себе на пользу, даже культуру. Поэтому оптимизм не должен быть бездумнымм и пассивным.

Приведу здесь еще одну мысль В.П. Зинченко о культуре, высказанную в 1990 г.: Наука, отчужденная от культуры, становится если не пустой, то наверняка заносиивой. Она может умереть, а может, мягко выражаясь, и навредить. Этого не происходит, когда культура сохраняется в качестве внутренней, опосредствующей форми любого акта научного познания и действия» (цит. по: Зинченко, 2016, с. 215-216).

Это один из самых ярких текстов В.П. Зинченко.

Гуманитаризация подготовки инженеров (Зинченко, 1986б). Эта статья написана в 1984 г. результате обобщения опыта работы кафедры эргономики МИРЭА с позиции профессионала-психолога, т.е. гуманитария, более четверти века занимающегося эргономикой и инженерной психологией. В статье речь идет о 
полноте требований, которым должен отвечать выпускник вуза, о том, чему не учат и чему следовало бы начать учить.

Мы начали с некоторых методологических и психологических аспектов обоснования необходимости гуманитаризачии высиего технического образования, пишет В.П. Зинченко. Имеются и общекультурнице ее основания. Культура по определению универсальна, интегративна. Наука вхоdum в нее в качестве составной части или, точнее, элемента, в котором должно быть отражено целое. Если этого нет, то наука оказьвается вне культурь. А культура, как и бессмертная булгаковская «свежесть», не имеет степеней. Оппозицией культуре может быть только бескультурье.

Статья заканчивается обсуждением педагогических аспектов гуманитаризации технического образования.

Изменение форм преподавания в ходе гуманитаризации технического образования должно затрагивать и предметное содержание излагаемого материала. Изменение того и другого требует не только предметной, но и специальной психолого-педагогической компетенции. Для предлагаемой перестройки форм обучения в технических вузах необходимо наличие психологически подготовленных преподавателей. Целесообразно начать создавать (хотя бы в качестве эксперимента) службу психологопедагогического обеспечения учебно-воспитательного процесса.

\section{Пятый блок}

Здесь представлены работы периода работы В.П. Зинченко во
ВНИИТЭ, опубликованные в сборниках этого института.

Статья 1976 г. (Горяинов, Зинченко, Лепский, 1976) в известном смысле подытоживает концепцию внешних и внутренних средств деятельности и посвящена теоретическим и методическим вопросам, связанным с повышением точности, достоверности и объективности разработки этих средств на различных этапах их проектирования. Внепние и внутренние средства деятельности операторов раскрыты в понятиях «информационная модель объекта управления» и «образно-концептуальная модель человека-оператора».

Важный момент состоит в том, что с помощью мощных универсальных вычислительных средств становится реализуемой экстериоризация внутренних средств деятельности (образов реальной или конструируемой в сознании обстановки) во внешний предметно-знаковый план деятельности. Становится возможной организация управляемого процесса отделения операций мышления от человеческой деятельности в их экстериоризированных, переданных машинам формах. Если система управления проектируется при значительном сохранении структуры и содержания деятельности, существующей в неавтоматизированном npomomune системы, то проектируемыми компонентами системы являются главным образом технические средства системы, ее информационное и программное обеспечение. Эти компоненты должны быть построены так, чтобы липь усилить и увеличить достоинства существующей деятельности, уменьшить и ослабить ее недостатки. Работа 1970 г. 
(Зараковский, Зинченко, 1970) подводит некоторые итоги. В ней излагается психологическая концепция анализа деятельности оператора, основная задача которого состоит в выявлении структуры трудового процесса, его мотивационно-целевой напряженности. Эта работа имеет существенное практическое значение.

\section{Заключение}

Статьи, включенные в этот обзор, свидетельствуют об исключительном творческом потенциале В.П. Зинченко, обусловленном, в частности, уникальной интеллектуальной средой, в которой он сформировался как ученый, в которой жил и работал и которую обогащал сам. Эту среду создавали люди, с которыми В.П. Зин- ченко не только обшался, но и дружил, которых ценил и любил. Это классики советской психологии, работавшие в Харьковском и Московском университетах, последние советские марксисты Э.В. Ильенков и А.А. Зиновьев, социологи Б.А. Грушин и Ю.А. Левада, изощренные аналитики сознания М.К. Мамардашвили и А.М. Пятигорский, методологи Г.П. Щедровицкий и Э.Г. Юдин, философы В.Н. Садовский и И.В. Блауберг, педагог В.В. Давыдов, математик В.А. Лефевр, писатель Ю.Ф. Карякин, лидеры советской авиационной и космической медицины и психологии. К әтим славным именам следует добавить главных конструкторов АСУ специального назначения и консультантов ІЦК КПСС.

\section{Список работ В.П. Зинченко по инженерной психологии}

Первый блок

1. Зинченко, В. П., Панов, Д. Ю. (1962). Узловые проблемы инженерной психологии. Bопросы психологии, 5, 15-30.

2. Зинченко, В. П., Леонтьев, А. Н., Панов, Д. Ю. (1964). Проблемы инженерной психологии. В кн. В. П. Зинченко, Д. Ю. Панов (ред.), Инженерная психодогия (с. 5-23). М.: Изд-во Московского университета.

3. Панов, Д. Ю., Зинченко, В. П. (1964). Построение систем управления и проблемы инженерной психологин. В кн. Д. Ю. Панов, В. П. Зинченко (ред.), Инженерная психология (с. 5-31). М.: Прогресс.

4. Зинченко, В. П., Майзель, Н. И., Назаров, А. И., Цветков, А. А. (1964). Анализ деятельности человека-оператора. В кн. В. П. Зинченко, Д. Ю. Панов (ред.), Ниженериая психология (с. 120-137). М.: Изд-во Московского университета.

\section{Второй блок}

6. Зинченко, В. П., Гордон, В. М. (1971). Анализ роли зрительной системы в процессах решения. В кн. Г. М. Зараковский, В. И. Медведев, В. М. Мунипов (ред.), Эргономика. Принцилы и режомендации (№ 3, с. 121-129). М.: ВНИИТЭ.

7. Зннченко, В. П. (1972). О микроструктурном методе исследования познавательной деятельности. В кн. В. П. Зинченко (ред.), Труды ВНИИТЭ. Эргономика (вып. 3, с. 5-11). М.: ВНИИТЭ. 
8. Зинченко, В. П., Труш, В. Д. (1978). Применение ЭВМ для исследований исполнительной и познавательной деятельности оператора. В кн. В. П. Зинченко (ред.), Труды ВНИИТЭ. Эргономика (вып. 15, с. 3-11). М.: ВНИИТЭ.

9. Панин, К. И., Зинченко, В. П. (1970). Построение информационных моделей в системах управления. В кн. В. П. Зинченко (ред.), Эргономика. Принципы и рекомендации (№ 1 (3), с. 55-90). М.: ВНИИТЭ.

\section{Третий блок}

10. Зинченко, В. П., Устинов, А. Г. (1975). Формообразование в дизайне и вопросы визуальной культуры. В кн. В. П. Зинченко (ред.), Труды ВНИИТЭ. Техииеская эстетика (вып. 11, с. 6578). М.: ВНИИТЭ.

11. Зинченко, В. П. (1986а). Эргономика и информатика. Вомросы философии, 7, 53-64.

12. Зинченко, В. П. (2002). Рефлексивные процессы в интернет-взаимодействиях (на примере шахматных игр). Международный науино-практииеский междисииплинарный журнал «Рефлексивные прочессы и управление», 2(1), 90-96.

\section{Четвертый блок}

13. Зинченко, В. П., Смолян, Г. Л. (1965). Человек и техника (Системы управления и инженерная психология). М.: Знание.

14. Зинченко, В. П. (1967). Некоторые способы повышения оперативности процессов приема и переработки информации человеком-оператором. В кн. А. Г. Чернов (сост.), Инженерная психология. Беседы по актуальным вопросам науки (с. 11-24). М.: Знание.

15. Зинченко, В. П. (1986б). Гуманитаризация подготовки инженеров. Вестник высией иколы, $10,22-31$

16. Зинченко, В. П. (1989). Культура и техника. В кн. Красная книга культуры (с. 55-69). М.: Искусство.

17. Зинченко, В. П. (2016). Философское наследие. М./СПб.: ЦГИ «Принт».

\section{Пятый блок}

18. Горяинов, В. П., Зинченко, В. П., Лепский В. Е. (1976). Проектирование внешних и внутренних средств деятельности. В кн. В. П. Зинченко (ред.), Труды ВНИИТЭ. Эргономика (вып. 12 , c. 125-164). М.: ВНИИТЭ.

19. Зараковский, Г. М., Зинченко, В. П. (1970). Анализ деятельности оператора. В кн. В. П. Зинченко (ред.), Эргономика. Припиипы и рекомендащии (№ 1, с. 33-54). М.: ВНИИТЭ.

Смолян Георгий Львович - главный научный сотрудник, Федеральный исследовательский центр «Информатика и управление» РАН, доктор философских наук.

Сфера научных интересов: социальные и психологические проблемы автоматизации управления, рефлексивное управление.

Контакты: gosha.smolyan@yandex.ru 


\title{
Vladimir Zinchenko and the Making of the Industrial Psychology in the USSR
}

\author{
G.L. Smolyan
}

"Federal Research Center "Informatics and Management" of the Russian Academy of Sciences (FIC IU RAS), 44/2 Vavilova Str., Moscow, 119333, Russian Federation

\begin{abstract}
The article presents the overview of works by V.P. Zinchenko in the field of industrial psychology from the beginning of 1960-ies to the middle of 1970-ies. These works formed the conceptual framework, determined the content and the borders of the subject domain of the industrial psychology (IP) as an independent branch of the applied psychology and played a pivotal role in the creation and development in 1960 the laboratory of industrial psychology in the Research Institute for Automatic Equipment, the main laboratory for the human factor integration in the designing and exploitation of man-machine information processing and control systems, and in 1969 - in creation and development of the department of ergonomics in the AllRussian Research Institute of Technical Aesthetics - the centre of methodological developments in the field of creation of technical equipment, controlled or used by man. The works of V.P. Zinchenko and his colleagues formed the methodological basis for numerous standards and guidebooks with practical recommendations on optimization of operator's behavior of the automatized systems, including the complex of the State All-Union Standards for the "Manmachine systems". All works by V.P. Zinchenko are thematically divided into five blocks.
\end{abstract}

Keywords: industrial psychology, man-machine system, distributed control system, manoperator, analysis of operator behavior, data model.

\section{References}

Goryainov, V. P., Zinchenko, V. P., \& Lepskii V. E. (1976). Proektirovanie vneshnikh i vnutrennikh sredstv deyatel'nosti [The design of outer and inner means of activity]. In V. P. Zinchenko (Ed.), Trudy VNIITE. Ergonomika (Iss. 12, pp. 125-164). Moscow: VNIITE.

Panin, K. I., \& Zinchenko, V. P. (1970). Postroenie informatsionnykh modelei v sistemakh upravleniya [Construction of data models in control systems]. In V. P. Zinchenko (Ed.), Ergonomika. Printsipy i rekomendatsii [Ergonomics: Principles and recommendations] (Iss. 1 (3), pp. 55-90). Moscow: VNIITE.

Panov, D. Yu., \& Zinchenko, V. P. (1964). Postroenie sistem upravleniya i problemy inzhenernoi psikhologii [Construction of control systems and issues of industrial psychology]. In D. Yu. Panov \& V. P. Zinchenko (Eds.), Inzhenemaya psikhologiya [Industrial psychology] (pp. 5-31). Moscow: Progress.

Zarakovskii, G. M., \& Zinchenko, V. P. (1970). Analiz deyatel'nostioperatora [Analysis of the operator's behavior]. In V. P. Zinchenko (Ed.), Ergonomika. Printsipy i rekomendatsii [Ergonomics: Principles and recommendations] (Iss. 1, pp. 33-54). Moscow: VNIITE. 
Zinchenko, V. P. (1967). Nekotorye sposoby povysheniya operativnosti protsessov priema i pererabotki informatsii chelovekom-operatorom [Some ways of raising operability of the process of information reception and processing by a man-operator]. In A. G. Chernov (Ed.), Inzhenernaya psikhologiya. Besedy po aktual'nym voprosam nauki [Industrial psychology. Discussions on the topical issues of science] (pp. 11-24). Moscow: Znanie.

Zinchenko, V. P. (1972). O mikrostrukturnom metode issledovaniya poznavatel'noi deyatel'nosti [On the microstructural method of investigation of the cognitive activity]. In V. P. Zinchenko (Ed.), Trudy VNIITE. Ergonomika [Works of VNIITE. Ergonomics] (Iss. 3, pp. 5-11). Moscow: VNIITE. Zinchenko, V. P. (1986a). Ergonomika i informatika [Ergonomics and informatics]. Voprosy Filosofii, 7, 53-64. Zinchenko, V. P. (1986b). Gumanitarizatsiya podgotovki inzhenerov [Humanitarization of the training of engineers]. Vestnik Vysshei Shkoly, 10, 22-31.

Zinchenko, V. P. (1989). Kul'tura i tekhnika [Culture and technology]. In Krasnaya kniga kultury [The Red Book of culture] (pp. 55-69). Moscow: Iskusstvo.

Zinchenko, V. P. (2002). Refleksivnye protsessy v internet-vzaimodeistviyakh (na primere shakhmatnykh igr) [Reflexive processes in the internet-interactions (on the example of chess play]. Refleksiomye Protsessy i Upravlenie, 2(1), 90-96.

Zinchenko, V. P. (2016). Filosofskoe nasledie [Philosophic legacy]. Moscow/Saint Petersburg: TsGI "Print".

Zinchenko, V. P., \& Gordon, V. M. (1971). Analiz roli zritel'noi sistemy v protsessakh resheniya [ПAnalysis of the role of visual system in the processes of decision-making]. In G. M. Zarakovskii, V. I. Medvedev, \& V. M. Munipov (Eds.), Ergonomika. Printsipy i rekomendatsii [Ergonomics. Principles and recommendations] (Iss. 3, pp. 121-129). Moscow: VNIITE.

Zinchenko, V. P., Leontiev, A. N., \& Panov, D. Yu. (1964). Problemy inzhenernoi psikhologii [Issues of industrial psychology]. In A. N. Leontiev, V. P. Zinchenko, \& D. Yu. Panov (Eds.), Inzhenernaya psikhologiya [Industrial psychology] (pp. 5-23). Moscow: Moscow University Press.

Zinchenko, V. P., Maizel', N. I., Nazarov, A. I., \& Tsvetkov, A. A. (1964). Analiz deyatel'nosti cheloveka-operatora [The analysis of the man-operator's behavior]. In A. N. Leontiev, V. P. Zinchenko, \& D. Yu. Panov (Eds.), Inzhenemaya psikhologiya [Industrial psychology] (pp. 120-137). Moscow: Moscow University Press.

Zinchenko, V. P., \& Panov, D. Yu. (1962). Uzlovye problemy inzhenernoi psikhologii [Key issues of industrial psychology]. Voprosy Psikhologii, 5, 15-30.

Zinchenko, V. P., \& Smolyan, G. L. (1965). Chelovek i tekhnika (Sistemy upravleniya i inzhenernaya psikhologiya) [Man and technology (Control systems and industrial psychology]. Moscow: Znanie.

Zinchenko, V. P., \& Trush, V. D. (1978). Primenenie EVM dlya issledovanii ispolnitel'noi i poznavatel'noi deyatel'nosti operatora [Application of ECM for the study of executive and cognitive behavior of operator]. In V. P. Zinchenko (Ed.), Trudy VNIITE. Ergonomika [Works of VNIITE. Ergonomics] (Iss. 15, pp. 3-11). Moscow: VNIITE.

Zinchenko, V. P., \& Ustinov, A. G. (1975). Formoobrazovanie v dizaine i voprosy vizual'noi kul'tury [Form making in design and the issues of visual culture]. In V. P. Zinchenko (Ed.), Trudy VNIITE. Tekhnicheskaya estetika [Works of VNIITE. Technical Aesthetics] (Iss. 11, pp. 65-78). Moscow: VNIITE.

Georgy L. Smolyan - chief reaseach fellow, Federal Research Center "Informatics and Management", Russian Academy of Sciences (FIC IU RAS), D.Sc.

Research area: social and psychological problems of automation and computerization, reflexive control.

E-mail: gosha.smolyan@yandex.ru 